\title{
ENTRE LÁPIS, CADERNOS E MEMÓRIAS: O MEMORIAL DO DEUTSCHER HILFSVEREIN AO COLÉGIO FARROUPILHA
}

DOI: http://dx.doi.org/10.1590/2236-3459/57937

\section{BETWEEN PENCILS, NOTEBOOKS AND MEMORIES: THE DEUTSCHER HILFSVEREIN MEMORIAL TO COLÉGIO FARROUPILHA}

\author{
Alice Rigoni Jacques \\ Colégio Farroupilha, Brasil.
}

$\cos 80$

Entre lápis, cadernos, fotografias, papéis, documentos e muitos outros artefatos da cultura escolar adentramos nos porões escuros, mofados e esquecidos das instituições escolares. Esta ação não se trata apenas de desenterrar histórias e vultos significativos do passado, embora a busca por ele apresente sempre um sutil e instigante fascínio. Estes espaços escolares podem ser reconhecidos como portadores de mensagens, vestígios da circulação de ideias pedagógicas e indicadores de práticas. Assim, o que se preservou desta materialidade pode ser compreendido como referência material, uma espécie de "ancoradouro para os indicadores" (Silva; Petry, 2012, p. 19).

A partir destas ações podemos conhecer um pouco mais a história das instituições escolares, que a partir das suas memórias revelam traços significativos do passado escolar, que permite transformá-lo em movimento e território de produção de conhecimentos, criação, divulgação, comunicação, preservação de bens e manifestações culturais.

Quando as escolas conscientizam-se da importância de salvaguardar seus registros documentais, buscam construir sua identidade institucional e, assim, tudo o que está guardado pode constituir-se em fontes de estudo para a História da Educação. Além disso, a produção de lugares de memórias pode diversificar as abordagens dos conteúdos de História, sendo os documentos dos arquivos escolares mais uma fonte possível de ser interrogada, construindo e desconstruindo o conhecimento ao sabor de novas hipóteses. 
No campo da História da Educação há empenho para a organização de espaços museológicos com vistas à preservar o patrimônio histórico-educativo, fundamental para a análise da historicidade de práticas educativas escolares, pelos distintos dispositivos que nos permitem narrar o cotidiano das escolas, revelar concepções educacionais e geracionais de um determinado tempo e lugar.

Silva e Petry (2012) destacam que o desafio dos museus escolares é sistematizar as expressões do fazer ordinário da escola sem apresentá-las como objetos estéreis, descontextualizados da vida escolar. Ao mesmo tempo indagam: "Como fazer esse trabalho sem aprisionar os objetos dando espaço para que se avive a riqueza de práticas inscritas nessa materialidade?" (p. 21).

O presente estudo analisa a implantação e a organização do acervo escolar do Colégio Farroupilha, de Porto Alegre/Rio Grande do Sul. O Memorial Do Deutscher Hilfsverein foi criado em 5 de junho de $2002^{1}$ para preservar e divulgar a história da mantenedora, a Associação Beneficente Educacional - ABE -, fundada em $1858^{2}$, e da Knabenschule des Deutschen Hilfsvereins, escola para meninos, criada em $1886^{3}$. Está localizado na Rua Carlos Huber, 425, no bairro Três Figueiras, zona Norte da cidade.

O acervo do memorial está composto por livros de atas da mantenedora e do Colégio Farroupilha; artefatos da cultura escolar; materiais dos laboratórios; máquinas de escrever, mimeógrafos, projetor de slides, episcópios, computadores da década de 1980, máquinas fotográficas; coleções de periódicos; mobiliário. A ordenação e organização do acervo adotou um sistema de registro por letras e números, em cadernos e em pastas com as fichas - de doação e de tombamento. As fichas descrevem o material, facilitando sua localização nos armários e gavetas. Atualmente, o registro dos materiais e documentos do acervo está sendo catalogado por meio de fichas digitalizadas.

Desde a fundação o Memorial $^{4}$ não se limita a constituir-se apenas em local de exposição, onde os documentos e objetos são mostrados como curiosidades, ainda que se Ihes proporcionem longas explicações sobre eles. Ele assume uma função mais ampla com o desenvolvimento de atividades multidisciplinares: espaço pedagógico, de pesquisa, exposição e museológico. Assim, não é apenas local de contemplação, de guarda e preservação de documentos, é lugar de pesquisa e de ensino.

Após algumas reformas o Memorial passou a ocupar novas instalações, projetadas para dar mais visibilidade às suas funções: museológicas, educacionais e de pesquisa. $O$ espaço possui uma área de $90 \mathrm{~m}^{2}$ e está dividido em três ambientes por painéis que trazem os nomes dos alunos formandos que frequentaram a escola desde 1920: um espaço de trabalho, para a coordenação e os pesquisadores, com mesa, computadores,

\footnotetext{
${ }^{1}$ Esse artigo se apoia em estudos anteriormente produzidos: Bastos, Almeida e Jacques (2008); Grimaldi (2012); Jacques e Grimaldi (2013); Bastos e Jacques (2014); Jacques e Almeida (2014).

2 A ABE também mantém um acervo de sua história, o qual está sendo gradativamente incorporado ao Memorial. Sobre a história da ABE e do colégio, ver Jacques (2013).

${ }^{3}$ Cabe assinalar que os integrantes da ABE, desde sua fundação, são nomes representativos da sociedade rio-grandense e porto-alegrense, da indústria e comércio, que fundaram várias instituições culturais e recreativas (Gans, 2004).

${ }^{4}$ A equipe do Memorial está constituída por Alice Rigoni Jacques, coordenadora; Milene Figueiredo, estagiária e bolsista (Ciee/CNPq); Gabriela Mathias de Castro (Fapergs/PUCRS) e Eduardo Hass (BPA/PUCRS) bolsistas de pesquisa.
} 
escâner e armário contendo parte do acervo documental; outro ambiente com réplica da sala de aula da década de 1950 e artefatos da cultura escolar desta época, e, por fim, um espaço com almofadas, quadro branco e projetor interativo, destinado ao atendimento das turmas de alunos da escola e demais visitantes.

Junto à proposta pedagógica da escola, o Memorial também se configura como uma ferramenta e um recurso à disposição dos professores e dos alunos. Aulas de História e de Estudos Sociais são programadas com tema previamente escolhido por professores ou que estão alinhadas com a matriz curricular. Hora do Conto Histórico, com temas sobre memória e patrimônio são apresentadas aos alunos, conteúdos sobre o início da povoação do Sul do país, museus da cidade, espaços culturais, pontos turísticos da cidade e meios de transportes utilizados antigamente. A inserção de documentos da instituição no trabalho em sala de aula, ou, ainda, de projetos envolvendo a história da instituição e da comunidade escolar também fazem parte do projeto pedagógico proporcionado pelo Memorial.

O Memorial é um espaço de forte significado, pois integra um projeto de valorização da escola e dos seus agentes: professores e alunos, em função de seu importante papel para garantir a indivíduos, de diferentes grupos sociais, o acesso ao conhecimento produzido pela humanidade. Por isso, o seu foco é a história do ensino, em todos os seus aspectos - o das instituições, o dos atores, o dos conteúdos.

Desde 2008 o Memorial está inserido no grupo de pesquisa Entre memórias e histórias da escola do Rio Grande do Sul: Do Deutscher Hilfsverein ao Colégio Farroupilha (1858-2008) (CNPq), que integra pesquisadores da Pontifícia Universidade Católica do Rio Grande do Sul, Universidade Federal do Rio Grande do Sul, Universidade do Vale do Rio dos Sinos, Colégio Farroupilha e conta com o apoio do Conselho Nacional de Desenvolvimento Científico e Tecnológico e da Fundação de Amparo à Pesquisa do Estado do Rio Grande do Sul. No ano de 2013 publicou-se o primeiro livro Do Deutscher Hilfsverein ao Colégio Farroupilha: memórias e histórias (1858-2008), reunindo algumas das pesquisas realizadas ${ }^{5}$, cujos objetos de estudos se referem aos elementos da cultura escolar e à história do Colégio Farroupilha.

Desde a sua criação busca-se promover condições para se estabelecer um diálogo entre o visitante, a pesquisa, os documentos e as exposições, com vistas à obter pontos de contato, diálogo, laços de afinidade e de apropriação com a história da escola e com a História da Educação. Assim, os museus escolares são espaços que possuem histórias, linguagens, propostas educativas e pedagógicas próprias.

\footnotetext{
${ }^{5} \mathrm{O}$ associativismo entre alemães e descendentes no Rio Grande do Sul; A Associação Beneficente e Educacional de 1858 e o Colégio Farroupilha; O Memorial do Deutscher Hilfsverein ao Colégio Farroupilha: espaço de educação e pesquisa; O velho casarão: um estudo sobre o Knabenschule des Deutsches Hilfsverein/Colégio Farroupilha (1895-1962); O Kindergarten do Deutscher Hilfsverein (1911-1929); A imprensa escolar do Colégio Alemão: Das Band e relatório mensal do Ginásio Teuto-Brasileiro Farroupilha (1929-1939); Um caminho de pregnâncias: os cinquenta anos de alfabetização da professora Lia Mostardeiro (1945-1994); Memórias juvenis nas páginas de um periódico: O Clarim (1945-1965); Cartilha, festa e escrita infantil: álbuns e cartas dos alunos do curso primário (1948-1966); Do carimbo à caneta vermelha: marcas de correção em cadernos escolares (1948/1958); Escola Técnica de Comércio Farroupilha (ETC/1949-1982); Meu diário: escritas de si na escola primária (1951-1957); Um retrato multicolorido da escola: os cadernos de uma aluna singular (1953-1957); À moda da escola: o uniforme feminino (1950); Lembrança em preto e branco: imagens de Primeira Comunhão (1958-1969); Territórios de professoras: currículo e práticas escolares nos registros de matéria (Bastos, Jacques; Almeida, 2013). 


\section{Referências}

BASTOS, Maria Helena Camara; ALMEIDA, Dóris Bittencourt; JACQUES, Alice Rigoni. Do Deutscher Hilfsverein ao Colégio Farroupilha: entre memórias e histórias (1858-2008). ENCONTRO DA ASSOCIAÇÃO SUL-RIO-GRANDENSE DE PESQUISADORES EM HISTÓRIA DA EDUCAÇÃO, 14, 2008. Anais... Pelotas: Asphe, 2008.

BASTOS, Maria Helena Camara; JACQUES, Alice Rigoni; ALMEIDA, Dóris Bittencourt (org.). Do Deutscher Hilfsverein ao Colégio Farroupilha/RS: memórias e histórias (18582008). Porto Alegre: PUCRS, 2013.

GANS, Magda. Presença teuta em Porto Alegre no século XIX (1850-1889). Porto Alegre: Ufrgs/Anpuh, 2004.

GRIMALDI, Lucas. Memorial Do Deutscher Hilfsverein ao Colégio Farroupilha: um lugar de memórias da escola (2002-2012). ENCONTRO DA ASSOCIAÇÃO SUL-RIOGRANDENSE DE PESQUISADORES EM HISTÓRIA DA EDUCAÇÃO, 18, 2012. Anais... Porto Alegre: PUCRS, 2012.

JACQUES, Alice Rigoni. A Associação Beneficente e Educacional de 1858 e o Colégio Farroupilha (1886). In: BASTOS, Maria Helena Camara; JACQUES, Alice Rigoni; ALMEIDA, Dóris Bittencourt (org.). Do Deutscher Hilfsverein ao Colégio Farroupilha/RS: memórias e histórias (1858-2008). Porto Alegre: PUCRS, 2013, p. 51-76.

JACQUES, Alice Rigoni; GRIMALDI, Lucas Costa. O Memorial do Deutscher Hilfsverein ao Colégio Farroupilha: um espaço de ensino e pesquisa (2002). In: BASTOS, Maria Helena Camara; JACQUES, Alice Rigoni; ALMEIDA, Dóris Bittencourt (org.). Do Deutscher Hilfsverein ao Colégio Farroupilha/RS: memórias e histórias (1858-2008). Porto Alegre: PUCRS, 2013, p. 77-91.

JACQUES, Alice Rigoni; ALMEIDA, Dóris Bittencourt. Acervo escolar do Colégio Farroupilha: lugar de ensino e de pesquisa. CONGRESSO IBEROAMERICANO DE HISTÓRIA DE LA EDUCACIÓN LATINOAMERICANA, 11, 2014. Toluca: Cihela, 2014.

BASTOS, Maria Helena Camara; JACQUES, Alice Rigoni. Liturgia da memória escolar Memorial do deutscher Hilfsverein ao Colégio Farroupilha (2002). Revista Linhas, Florianópolis, v. 15, n. 28, 2014, p. 49-76.

SILVA, Vera Lucia Gaspar; PETRY, Marília Gabriela (orgs.). Objetos de escola: espaços e lugares de constituição de uma cultura material escolar (Santa Catarina - séculos XIX e XX). Florianópolis: Insular, 2012, p. 19-24.

ALICE RIGONI JACQUES é estudante do curso de doutorado em Educação na Pontifícia Universidade Católica do Rio Grande do Sul e coordenadora do Memorial do Deutscher Hilfsverein ao Colégio Farroupilha.

Endereço: Rua João Ernesto Schmidt, 251/708 - 91210-125 - Porto Alegre - RS Brasil.

E-mail: alice rigoni@hotmail.com.

Recebido em 13 de julho de 2015.

Aceito em 9 de agosto de 2015. 